\title{
Algunas observaciones sobre las reliquias del Arca Santa de Oviedo y nueva edición del Acta de Apertura de I075
}

Valeriano Yarza Urquiola UPV-EHU

Some notes about relics of the Sacred Chest of Oviedo and new edition of the Certificate of the Opening in 1075

EVALUADO Y ACEPTADO: II-IO-2O2O

Territorio, Sociedad y Poder, $\mathrm{N}^{0}$ I5, 2020 [PP. 67-85] 
Resumen: La relación de las reliquias del Arca Santa de la catedral de Oviedo es muy diferente en los documentos de fines del s. XI y en los de inicios del s. XII. Comparamos y analizamos las causas de sus diferencias. Proponemos algunas lecturas nuevas en documentos fundamentales y ofrecemos la edición

Авstract: The list of the Relics of the Sacred Chest from the catedral of Oviedo is very different in these documents: one, from the end of the $\mathrm{XI}^{\text {th }}$ century; the second, from the beginnings of the XII ${ }^{\text {th }}$ century, We compare them and we analyse the reasons of their differences. We propose some new readings on basic crítica de uno de ellos, esto es, el Acta de apertura del Arca en 1075.

Palabras clave: Reliquias. Catedral de Oviedo. Siglos XI y XII. Disparidad en los testimonios. Propuesta de cambios en algunos textos.

documents and we offer the critic edition about one of them. The Certificate of Chest opening in 1075.

Keywords: Relics. Cathedral of Oviedo. XI and XII centuries. Disparity between the testimonies. Suggestion of changes in some texts. 


\section{A. PRIMEROS TESTIMONIOS SOBRE EL ARCA SANTA Y SUS RELIQUIAS. FINES DEL $S$. xi}

Los dos testimonios más antiguos sobre el Arca Santa de la catedral de Oviedo y sus reliquias son: a) El Acta de la solemne apertura de la misma ante el rey Alfonso VI, su hermana Urraca y la jerarquía eclesiástica en I075. b) La inscripción que recoge el evento de la apertura, grabada en la cubierta de plata de la propia Arca, elaborada, según todos los indicios, a fines del s. XI, sin fecha enteramente legible, borrada actualmente en su parte final (se lee hera sine dubio $M^{a} C^{a} a t q$ ).

En el Acta se dice que las reliquias se habrían agrupado en Toledo tras la conquista musulmana y encerradas en el Arca, que habría sido llevada a Oviedo, no fuera que se perdieran o se destruyeran. El Arca habría permanecido escondida y desconocida hasta que quisieron abrirla en tiempos del obispo Poncio (IO25-IO35), pero los abades y clérigos, cegados por un resplandor de luz enorme, no pudieron lograrlo. La apertura se consiguió en presencia del rey Alfonso VI de León el día I3 de marzo de 1075, quedando a la vista las reliquias.

En la inscripción se lee que fue el rey Alfonso VI quien hizo el Arca para receptáculo de las reliquias, adornada magníficamente en su parte exterior con el revestimiento de plata que cubre todo el cofre, y que su contenido, las reliquias, lo pudo ver toda la provincia en la era ¿MCXIII?, es decir, año IO75, cuando se procedió a su apertura.
En el Acta de apertura del Arca de I075 se recoge, en lo que se refiere a las reliquias, lo siguiente (transcribimos el texto directamente de los diplomas del Archivo de la catedral de Oviedo, serie B, carpeta 2, $n^{\circ}$ 9 A y no 9 B: cfr Fernández Conde, Alonso Álvarez, 2017: $\left.55-81^{1}\right)$ :

Anno ab incarnatione Domini nostri Ihesu Christi Mo LXXVo... Nam mediante quadragesima, III idus martii, VIa feria, circa horam terciam, episcopi et presbiteri missarum solemniis celebratis cum concentu psallencium clericorum, ad locum usque perueniunt destinatum ubi reconditum habebatur munus tam copiosum. Leui autem motu cum magno timore aperientes, turibulis hinc atque illinc timiamatha fumiuoma flagrancia reddentibus, repererunt hoc in propatulo quod a Deo poposcerant, scilicet incredibile thesaurum. Id est, de ligno Domini. De cruore Domini. De pane Domini, id est, de cena ipsius. De sepulchro Domini. De terra sancta ubi Dominus stetit. De uestimento Sancte Marie et de lacte ipsius uirginis ac genetricis Domini. De uestimento Domini sorte partito et de sudario eius. Reliquias de

\footnotetext{
I Véase en Apéndice el texto entero con la edición crítica elaborada por nosotros.
} 
sancto Petro apostolo, sancti Thome, Bartholomei apostoli. De ossibus prophetarum, sanctorum Iusti et Pastoris, Adriani et Natalie, Mame, Iulie, Verissimi et Maxime germani, Bauduli, Pantaleonis, Cipriani, Eulalie, Sebastiani, Cucufatis. De pallio sancti Sulpicii, sancte Agate, Emeterii et Celedoni, sancti Iohannis Babtiste, sancti Romani, sancti Stephani prothomartiris, sancti Fructuosi, Augurii et Eulogii, sancti Victoris, sancti Laurentii, sanctarum Iuste et Rufine, sancti Seruandi et Germani, sancti Liberi, sanctarum Maxime et Iulie, sancti Cosme et Damiani, sancti Sergii et Bachi, sancti Iacobi fratris Domini, sancti Stephani pape, sancti Christofori, sancti Iohannis apostoli, uestimentum sancti Tirsi, sancti Iuliani, sancti Felicis, sancti Andree, sancti Petri exorciste, sancte Eugenie, sancti Martini, sanctorum Facundi et Primitiui, sancti Vincenti leuite, sancti Fausti, sancti Iohannis, sancti Pauli apostoli, sancte Agne, sancti Felicis, Simplicii, sancti Faustini et Beatricis, sancte Petronille, sancte Eulalie Barcinonensis. De cineribus sanctorum Emiliani diaconi et Iheremie martirum, sancti Rogelli, sancti Serui Dei martiris, sancte Pompose, sanctorum Ananie, Azarie et Misaelis, sancti Sportelii et sancte Iuliane et aliorum quam plurimorum, quorum numerum sola Dei sciencia colligit.

La inscripción del Arca tiene varias lagunas y palabras cortadas y ha sido estudiada, reconstruida y transcrita, en varias lecturas ope ingenii, por diferentes especialistas (Flórez, I765: 70-73; Gómez Moreno, 1934: 28-30; Bango, 20II: II-67; García de Castro, 20I6: I2II62; Rico, 2017: 37-53.), de los que tomamos el texto a la vez que hacemos algún cambio por nuestra parte, como seguidamente comentaremos, siendo nuestra la numeración):

${ }^{\mathrm{O}}$ Omnis conuentus populi Deo dignus catolici cognoscat, quorum inclitas venera(n) tur reliquias intra preciosisima presentis arce latera, hoc est: ${ }^{2}$ De ligno plurimum sive de cruce Domini. ${ }^{3}$ De vestimento illius quod per sorte diuisu(m) est. ${ }^{4}$ De pane delectabili unde in cena usus est. 'De sepulcro dominico eius atque sudario et cruore sanctisimo. ${ }^{6} \mathrm{De}$ terra sancta qua(m) piis calcavit tunc vestigiis. ${ }^{7} \mathrm{De}$ vestimentis virginis matris eius Marie. ${ }^{8} \mathrm{De}$ lacte quoque illius, quod multum est mirabile. ${ }^{9}$ His pariter coniuncte sunt quedam sanctorum maxime prestantes et reliquie, quorum prout potuimus hic nomina subscripsimus, hoc est, de sancto Petro, de sancto Tome, sancti Bartolomei. ${ }^{10}$ De osibus profetarum et de omnibus apostolis et de aliis quam plurimis sanctis quoru(m) nomina sola Dei sciencia coligit. "His omnibus egregius rex Adefonsus, humili devocione preditus, fecit hoc receptaculum pignoribus sanctorum penitus insignitum, exterius adornatum non vilibus artis operibus, per quod post vitam eius mereatur consorcium illorum in celestibus sanctorum regnis et suis adiuvari precibus. ${ }^{12} \mathrm{Hec}$ quidem salutifera atque veneranda munera novit omnis provincia in hera sine dubio $M^{a} C^{a}$ atque XIIIa per manus et industriam clericorum et presulum, qui propter hoc convenimus cum dicto Adefonso principe cum germana letissime Vrraca dicta nomine, quibus redemtor omnium concedat indulgenciam et suorum pecatorum veniam per hec sanctissima pignora apostolorum et martirum, hoc est, de sancti Iusti et Pastoris, Adriani et Natalie, Mame, Iulie, Virisimi et Maximi germani, Bauduli, Pantaleonis, Cipriani, Eulalie et Sebastiani, Cucufatis, de pallio sancti Sulpicii.

I. Como se puede observar, la semejanza entre el texto de ambos documentos, en lo que hace a las reliquias, es casi completa, siendo más breve necesariamente el de la inscripción por falta de espacio. Hay que decir que la fecha de la inscripción en el Arca hera $M^{a} C^{a}$ atque $X I I I^{a}$, es decir, el ańo I075 (cfr apart. I2), aceptada por la mayoría de especialistas, fue ideada por Gómez Moreno acudiendo al Acta de apertura, ya que hoy en día no 
se lee su final, es decir, -ue XIII ${ }^{a}$. Pero muy probablemente tal fecha era la que aparecía inicialmente, ya que la inscripción conmemora el hecho de la apertura y, por tanto, debía señalar forzosamente la fecha del evento.

En los dos documentos del Acta de apertura, 1. 92 de nuestra edición, se lee claramente sub hera $M^{a} C^{a}$ $X I I I^{a}$, 'en la era MCXIII', es decir, año I075. En cualquier caso, el Arca encargada por Alfonso VI estaba en la catedral de Oviedo en IIO2, porque «Pelayo, en las interpolaciones a la Adefonsi tertii chronica, da noticia de su instalación en la Cámara Santa ese año» (Alonso Álvarez, 20II: 23, n. 78).

El Acta de apertura se encuentra en dos copias del s. XIII guardadas en la catedral de Oviedo y su autenticidad ha sido puesta en duda por algunos estudiosos (Gambra, I997: 6I-62), pero Fernández Conde y Alonso Álvarez (2017: 63, n. I9) desmontan sus argumentos. A nuestro juicio, el texto de la inscripción del Arca, tan parecido en su contenido al de la apertura, avala por completo la originalidad del Acta. Es más, se puede decir que la inscripción es una adaptación del Acta de apertura. La fecha de elaboración del Arca y su inscripción, en opinión de los estudiosos arriba mencionados, se puede localizar entre los años IO75-IIO2. La inscripción habría tomado su texto del Acta, que sería unos pocos años anterior.

La frase, sospechosa a ojos de Gambra, presente en el Acta de apertura, 1. 3I-33 de nuestra edición (véase en Apéndice): sacrificiis et orationibus intentos clericos tholetanos illic habitantes esse precepit et reliquos Romanum ritum tenentes ortatur Dominum precibus flagitare ('ordenó [el rey Alfonso] que los clérigos toledanos que vivían en Oviedo se aplicaran en sacrificios y oraciones y anima a los demás, practicantes del rito romano, a suplicar al Señor'), significa que los clérigos de Toledo, todavía dominada en 1075 por los musulmanes, practicaban el rito mozárabe, hispánico, y los demás, de zonas ya reconquistadas, pertenecientes a la monarquía leonesa de Alfonso VI, seguían por esas fechas el rito romano casi todos. Por tanto, el Acta no hace sino recoger la realidad histórica.

No puede sorprender, a pesar de sus vaivenes, esta actitud del rey, ya que en el concilio de Coyanza de
I055 convocado por Fernando I, padre de Alfonso, se había aprobado la acogida del rito romano y a partir de I074 el papa Gregorio VII se esforzó sin cesar por que se estableciera en toda la Península la liturgia romana. En I076 el rey Alfonso remite al abad Hugo de Cluny un escrito pidiéndole que envíe algunos monjes de su monasterio a Sahagún para que enseñaran la doctrina, las costumbres y las ceremonias cluniacenses, todas ellas de rito romano. Finalmente, en Io8o, el concilio de Burgos aprobó lo que ya era, con matices, un hecho en casi todas partes, esto es, la sustitución del rito mozárabe por el hispano.

En cuanto al título de imperator hay que decir que desde principios del s. $\mathrm{x}$ los reyes de León utilizaron el título de imperator. Su padre, Fernando I, se había llamado rex imperator y el propio Alfonso VI se nombró en I077 imperator totius Hispaniae.

2. La inscripción recoge las reliquias que cita el Acta de I075: de la cruz de Cristo, de su vestido, del pan de la última cena, del sepulcro y del sudario del Señor y de su sangre; de la tierra que pisó el Señor. Del vestido y de la leche de la Virgen. Reliquias de san Pedro, santo Tomás, san Bartolomé. De los santos y mártires, de los santos Justo y Pastor, Adrián y Natalia, Mamés, Julia, Verísimo y Máxima, hermanos, Baudilio, Pantaleón, Cipriano, Eulalia, Sebastián, Cucufate, del manto de san Sulpicio...

Por nuestra parte, hemos eliminado del texto reconstruido de la inscripción del Arca (apart. I2) los nombres Cosme et Damiani, incluidos ope ingenii por Morales y aceptados por todos los estudiosos, y los hemos sustituido por el de Mame, es decir, san Mamés (López Fernández, 2004: 182, n. 36), santo oriental, como aparece en el Acta de apertura, en la que dichos santos Cosme y Damián son citados más adelante. La lectura correcta es Mame, un genitivo construido junto a un nominat. Mames y un acusat. Mamem, habituales en los relatos hagiográficos. Para el genit. encontramos en el relato que transmiten los códices del Pasionario Hispánico las formas Mametis y Mames. Más arriba se encuentra citado en la inscripción santo Tomás, cuya declinación es Thomas, genit. Thome. En la inscripción 
aparece incorrectamente de sancto Tome, ablat. + genit., y en el Acta, correctamente, sancti Thome. También se encuentran en el Acta de apertura Cosme, genit. de Cosmas, y Agne, genitivo de Agnes. En cuanto al espacio ocupado por Mame en la inscripción, sin duda es mucho menor que el de Cosme et Damiani, pero, como dice Rico, p. 50, «en la segunda parte de la inscripción los caracteres tienden a ser más anchos que en la primera... y da asimismo la impresión de que a partir de la línea 9 el recurso a las letras embutidas disminuye considerablemente».

Hemos mantenido en el texto de la inscripción (apart. I2) la lectura Maximi, presente en el Arca y en las dos copias del Acta de apertura, que debiera ser Maxime, es decir, Maximae, mujer, no varón, tal como se recoge en los relatos hagiográficos. En la edición del texto del Acta, sin embargo, hemos escrito Maxime, porque así aparece de nuevo líneas más abajo, junto a Iulie, en el diploma $A \operatorname{del}$ Acta de apertura.

Hemos anotado (apart. I2) con minúscula germani, ya que se refiere a que Julia, Verísimo y Máxima eran hermanos, concertando germani o bien con el incorrecto Maximi o bien constituyendo una aposición de los tres mártires. En el relato hagiográfico transmitido por los códices del Pasionario Hispánico no se alude a que fueran hermanos, pero la tradición sí lo recoge. Seruandi et Germani aparecen citados más adelante en el Acta de apertura.

Hemos corregido la lectura Cucufati, presente en las dos copias del Acta de apertura, por la grafía correcta Cucufatis, genit. de Cucufas. En la inscripción del Arca (apart. I2) solo se lee Cucu.

Finalmente, hemos eliminado del texto (apart. I2) de la inscripción Felicis, lectura reconstruida por Morales y aceptada por los especialistas, y la hemos sustituido por De pallio sancti, tal como se recoge en el Acta de apertura, que en la inscripción habría sido De palio sci, tres letras más que el Felicis imaginado por Morales. En todo caso, De palio sci, más la s- inicial de Sulpicii, es decir, Depalioscis, y Felicis comparten, como es evidente, varias letras, que habrían inducido al historiador a escribir Felicis. Por su parte, Felicis aparece citado más adelante en el Acta en dos ocasiones.
3. La relación de los santos citados en ambos documentos ha sido tomada en su mayor parte del Pasionario Hispánico, colección de relatos de mártires de diversos países formada en los monasterios de Cardeña y Silos en los siglos x y XI para su lectura en la liturgia (FÁBREGA, I953). Los santos no están citados siguiendo el calendario litúrgico de sus festividades per circulum anni, tal como aparecen en los códices del Pasionario Hispánico, sino que han sido tomados, según parece, de un códice del s. XI y anotados sin ningún orden. A nuestro juicio, la relación de los santos incluidos en el Pasionario Hispánico y presentes en la inscripción del Arca Santa y en el Acta de apertura podría estar tomada del códice Paris, $\mathrm{BnF}$ nouv. acq. lat. $2179(S)$, s. XI, escrito en Silos, o de una copia suya. Actualmente no se encuentran en el citado manuscrito por pérdida de folios los relatos martiriales de Eulalia de Mérida, Román, Servando y Germán, Cosme y Damián, Andrés, Facundo y Primitivo y Fausto y compańeros.

Pertenecen al Pasionario Hispánico del s. X los relatos hagiográficos de Pedro, Tomás, Bartolomé, Justo y Pastor, Adrián y Natalia, los hermanos Julia, Verísimo y Máxima, Pantaleón, Cipriano, Eulalia de Mérida, Sebastián, Cucufate, Águeda, Emeterio y Celedonio, Román, Esteban, Fructuoso, Augurio y Eulogio, Lorenzo, Justa y Rufina, Servando y Germán, Máxima y Julia (de nuevo), Cosme y Damián, Santiago hermano del Señor, Cristóbal, Juan apóstol, Tirso, Julián, Félix (de Nola o de Gerona), Andrés apóstol, Eugenia, Facundo y Primitivo, Vicente levita, Fausto, Juan (probablemente el apóstol de nuevo), Pablo apóstol, Inés, Félix (de Nola o de Gerona), Eulalia de Barcelona, Ananías, Azarías y Misael (personajes del Antiguo Testamento presentes en el relato del martirio de Facundo y Primitivo y en el relato de Juliana, santa cuya Pasión se halla en el Pasionario del s. XI).

En total se hace referencia a protagonistas de 35 relatos martiriales de los 63 de que consta el Pasionario Hispánico del s. x. Es también citado Liberio, obispo de Mérida, s. III-IV, cuyo nombre se encuentra en la Pasión de santa Eulalia de Mérida. 
En el Pasionario del s. XI se hallan los relatos martiriales de Mamés, Baudilio, Víctor (de Marsella o de Braga o de Cesarea de Mauritania o de Alejandría), Sergio y Baco, Juliana, en total 5 , de las 60 narraciones que contiene el Pasionario Hispánico del s. XI.

El resto de santos, cuyos nombres no se encuentran en el Pasionario Hispánico, mártires todos excepto Sulpicio, obispo de Bourges en el s. VI, pero aparecen en el Acta de apertura del Arca, son los siguientes: Sulpicio, Juan Bautista, Esteban papa, Pedro exorcista, Martín (seguramente Martín I, papa en el s. viI, considerado mártir), Simplicio, Faustino y Beatriz, Petronila, Emiliano diácono y Jeremías, Rogelio, Siervo de Dios, Pomposa, Esportelio.

Juan Bautista fue decapitado, s. I, en Maqueronte (Jordania). Esteban papa, s. III, Pedro exorcista, Faustino y Beatriz, s. IV, y Martín papa, s. VII, todos ellos fueron inmolados en Roma. Simplicio, primer obispo de Olbia (Cerdeña), habría muerto martirizado en 304 por Diocleciano. Petronila, que habría vivido en el s. I en Roma, es considerada, según el santoral, virgen y mártir.

Emilas, Emilio o Emiliano diácono y los cuatro siguientes santos son mártires cordobeses de la época de la dominación musulmana (s. Ix). No hemos hallado noticias del último santo, Esportelio.

Toda esta relación de santos, exceptuados los romanos y cordobeses ańadidos al final, apuntan, como hemos dicho, a una copia del códice silense $S$ o similar, presente en Oviedo, quizá procedente del monasterio de Sahagún, tan relacionado con el rey Alfonso VI, que habría servido de transmisor de los nombres de los protagonistas. Los nombres de los mártires cordobeses habrían llegado de Córdoba a Sahagún, como los de otros santos del Pasionario Hispánico, Acisclo, Zoilo, etc. La llegada a Oviedo de todos estos nombres debió de producirse en la segunda mitad del s. XI, una vez formado el Pasionario Hispánico del s. XI. Parece tarea inútil el intentar averiguar las razones de la entrada de unos santos del Pasionario Hispánico y la no inclusión de otros en la relación de nombres de la inscripción y del Acta de apertura. Da la impresión de haber sido elegidos al azar, salvo en el caso de nombres consagrados.

\section{B. TESTIMONIOS DEL S. XII SOBRE EL ARCA SANTA Y SUS RELIQUIAS}

Del s. XII se conservan dos documentos relacionados con las reliquias: I) El Liber Testamentorum, cartulario de la diócesis de Oviedo, datado hacia III8, encargado por Pelayo, obispo de Oviedo entre IIOI-II3O y II42II 43. 2) El manuscrito Valenciennes 99, que contiene en dos folios un texto que describe las reliquias ovetenses. Este último texto se encuentra igualmente en el códice Burgo de Osma, Biblioteca del Cabido 8, de finales del s. XII o principios del xiII, y en el manuscrito British Library, Harley 2253, s. XIV.

I. El Liber Testamentorum cuenta, en un relato fabuloso, que el Arca, construida por los discípulos de los Apóstoles, llegó de Jerusalén a Toledo por África en tiempos de Sisebuto (612-62I) y, una vez derrotado por los musulmanes y muerto el rey Rodrigo (7II), de Toledo a Oviedo, donde estuvo guardada hasta que el rey Alfonso el Casto (c. 760-842) construyó el templo de San Salvador. En cuanto al contenido del Arca, el Liber Testamentorum dice lo siguiente (cfr Sanz, 1995, p. 456-46I):

Tenet enim cristallinam ampullam cum de cruore Domini, fuso uidelicet a latere illius imaginis quam quorumdam perfidia iudeorum ad pressionem ueritatis Crucifixi ceream affigens ceree cruci, perforauit in latere de quo exiuit sanguis et aqua, ad ipsorum iudeorum perfidiam conuinciendam, et sancte ecclesie fidem roborandam. De ligno Domini. De Sepulchro Domini. Partem ex spine corone. De Sindone Domini. De tunica Domini. De pannis ubi iacuit in presepio inuolutus. De pane quo satiauit Dominus quinque milia hominum. De pane cene Domini. De manna que pluit Dominus filiis Israhel. De terra montis Oliueti, ubi Dominus ascensurus pedes tenuit. De terra ubi Dominus pedes tenuit quando Lazarum resuscitauit. Et de sepulchro ipsius Lazari. Et, quod est dignum summa 
ueneratione, in ecclesia ipsa principali Sancti Saluatoris habetur una sex hydriarum in quibus Dominus in nupciis aquam uertit in uinum, ut euangelica monstrat ueritas, integra. De lacte Matris Domini. De uestimento eius. De pallio quod dedit ipsa Regina Celi Hildefonso, Toletane sedis archiepiscopo, pro laudibus in honore sancte ipsius uirginitatis celebratis, ubi ipse episcopus gloriose contulit, aduersus heresiarcas eluidium atque Iouinianum, sic dicens illi circunstantibus tam angelorum quam etiam sanctorum multiplicibus choris inennarrabili luce circunscriptis: 'accipe hoc munus quod tibi de thesauro Filii mei attuli'. Manus Sancti Stephani. Sandale dextrum Sancti Petri apostoli. Frons Iohannis Babtiste. De capillis Innocentum et articulis digitorum. De ossibus trium puerorum Azarie, Ananie et Misahelis. Ex capillis unde Martha et Maria pedes Domini terserunt. De lapide cum quo sigillatum est sepulchrum Domini. De oliua de monte Oliueti. De petra montis Sinay. De pallio Elie. De sudario Domini. Partem piscis assi et fauum mellis. Multa praeterea sanctorum ossa prophetarum. Multa etiam aliorum sanctorum, omnium martirum et confessorum et uirginum diuersa pignora ibi in capsis aureis tenentur recondita, que nos scribere omnia ipsa abnegat infinitas. Crux ibi monstratur opere angelico fabricata spectabili modo.

Como se puede ver, la relación de reliquias que ofrece el Liber Testamentorum tiene algunas coincidencias con las del Acta de apertura de 1075 y muchas diferencias. Las primeras son: restos de la sangre de Cristo, de la cruz, del sepulcro, de su vestido, del pan de la última cena, de la tierra pisada por él, de la leche de la Virgen, de su vestido, de los huesos de Azarías, Ananías y Misael, del sudario de Cristo, de los huesos de los profetas.

Las diferencias son por adición y por omisión. El Liber Testamentorum añade: restos de la corona de espinas del Señor, de su sábana o sudario, de sus pañales, del pan con el que sació a cinco mil hombres, del maná dispensado por Dios a los israelitas, de tierra del monte de los Olivos, de tierra en la que el Señor tuvo sus pies durante la resurrección de Lázaro, del sepulcro de Lázaro, una de las seis tinajas en las que Jesús convirtió el agua en vino, restos del manto que regaló la Virgen a Ildefonso obispo de Toledo, las manos de san Esteban, la sandalia derecha de san Pedro, la frente de Juan Bautista, restos de los cabellos de los Santos Inocentes y articulaciones de sus dedos; de los cabellos con los que Marta y María limpiaron al Señor, de la roca con la que se selló el sepulcro del Señor, de la oliva del monte de los Olivos, de la piedra del monte Sinaí, del manto de Elías, parte de un pez asado y un panal de miel.

Por contra, en el Liber Testamentorum se omiten los nombres de todos los santos cuyos relatos se recogen en el Pasionario Hispánico, desde san Pedro a santa Juliana, citados en general: 'muchas reliquias de otros santos, de todos los mártires, de confesores y vírgenes'. El cambio, pues, es casi total en menos de los cincuenta ańos que van desde la redacción del Acta de apertura (I075) a la elaboración del Liber Testamentorum (c. III8). Y todo ello en la misma ciudad, Oviedo.

Las reliquias añadidas seguramente son introducidas, por un lado, para compensar la omisión de los nombres de los mártires del Pasionario Hispánico y, por otro, para reforzar el origen que el Liber Testamentorum otorga al Arca, esto es, Jerusalén. Con todo ello, la historia del Arca se ve engrandecida y Toledo, disminuida. Ese debió de ser el objetivo de la confección de la lista por parte de Pelayo y sus colaboradores, rebajar el prestigio de Toledo, reconquistada en I085, de cuya sede había sido nombrado obispo, un año más tarde, Bernardo de Cluny, dos años después proclamado primado de Hispania (I088). En la narración del Liber Testamentorum la figura no es Alfonso VI, muerto en IIo9, antes de la elaboración del Liber Testamentorum, sino Alfonso II el Casto, rey de Asturias en los. ss. viII-IX.

Por tanto, se ha pasado en pocos ańos de la exaltación del rey Alfonso VI, de la historia de la llegada del Arca desde Toledo y de la relación de reliquias de los mártires del Pasionario Hispánico a una nueva hagiografía. Se trata de un problema de prestigio de las sedes episcopales: el Liber Testamentorum defiende la sede de 
Oviedo y se olvida del resto, Toledo, Santiago..., convertidas en rivales. El obispo Pelayo de Oviedo, tras el traslado a Toledo de Alfonso VI y su muerte en IIo9, da un vuelco a la historia y la leyenda en favor de su sede.

2. Manuscrito Valenciennes 99. Es un códice del s. IX, que en su inicio, ff. $2 \mathrm{v}-3 \mathrm{r}$, tiene intercalado un breve texto, ańadido en el s. XII, en el que se narra el traslado del Arca Santa desde Jerusalén a Oviedo y se da la relación de sus reliquias.

En el Catalogue général des manuscrits des bibliothèques publiques de France. Départements. Tome xxv. Poitiers [par A.F. Lièvre et Auguste Molinier], Valenciennes [par Auguste Molinier], Paris, E. Plon, Nourrit et $\mathrm{C}^{\mathrm{ie}}$, I894, p. 229-230, se data el texto ańadido como perteneciente al s. XI.

Sin embargo, años más tarde, H. Omont, «Manuscrits illustrés de l'Apocalypse aux $\mathrm{IX}^{\mathrm{e}}$ et $\mathrm{X}^{\mathrm{e}}$ siècles", Bulletin de la Société Française de reproductions de manuscrits a peintures 6, Paris (1922), p. 62-95, dice (p. 83) que el texto fue copiado sin duda por un monje del s. XII, en lo que están de acuerdo la mayoría de estudiosos (Alonso Álvarez, 2007-2008: 23; 2017: 54). La referencia del artículo de Omont nos ha sido facilitada por el profesor J. C. Martín.

Este es el texto completo del documento que transmite el códice de Valenciennes en transcripción hecha directamente por nosotros:

\section{Dilectissimi fratres in Christo, qui Deum in} celis atque in terra omnia quecumque uult posse non dubitatis, manifesta uobis relatione et firma ueritate intimamus que uos audientes hortamur, ut fide uera credatis quod Deus mirabili potentia et secreto suo consilio arcam, de lignis imputribilibus a discipulis Apostolorum factam, innumeris Dei magnaliis plenam, ab urbe Iherosolima transtulit in Affricam, ab Affrica in Chartaginem, a Chartagine in Toletum, a Toleto in Asturias in ecclesia Sancti Saluatoris, loco qui dicitur Ouetum.

Que archa ibidem est aperta, in qua inuenerunt plures arcellas aureas, argenteas et eboreas, quas aperire presumentes uiderunt oculis in eis contineri subscripta Dei magnalia appositis scriptis, queque per se manifestissime declarata. Inuenerunt siquidem ibi cristallinam ampullam cum cruore fuso de latere illius imaginis, quam quidam fideles ad similitudinem Christi fecerunt, quam perfidi Iudei antiqua perfidia obcecati ligno affixerunt et lancea ut ueri uiui Christi latus percusserunt, ex qua ad fidem passionis Christi astruendam exiuit sanguis et aqua. De uera cruce Domini maximam partem. De sepulcro Domini. Partem spinee corone. De sindone Domini. De sudario Domini. De tunica Domini. De pannis quibus Dominus iacuit in presepio inuolutus. De pane quo saciauit Dominus quinque milia hominum. De pane cene Domini. De manna quod pluit Dominus filiis Israel. De terra montis Oliueti ubi Dominus in celum ascensurus pedes tenuit. De terra ubi pedes tenuit quando Lazarum suscitauit. De sepulcro ipsius Lazari. De lacte matris Domini. De capillis et uestimentis eius. Pallium quod dedit ipsa regina celi Ildefonso Toletane sedis archiepiscopo. De pallio Elihe. Manus sancti Stephani prothomartiris. Sandale dextrum beati Petri apostoli. Frons sancti Iohannis Babtiste et de capillis eius. De capillis et de ossibus Innocentum et articulis digitorum. De ossibus trium puerorum, Ananie, Azarie et Misaelis. De capillis cum quibus Maria Magdalene tersit pedes Domini. De lapide cum quo sigillatum est sepulcrum Domini. De oliua quam Dominus tenuit in ramis palmarum. De petra montis Synay supra quam Moyses ieiunauit. De uirga cum qua Moyses diuisit mare Rubrum filiis Israel. Partem piscis assi et fauum mellis. Multa preterea sanctorum ossa prophetarum, multa et aliorum sanctorum martirum, confessorum et uirginum diuersa ibi pignora in capsis aureis, argenteis et eboreis tenentur recondita, quorum numerum sola Dei scientia colligit.

Extra arcam ipsam habentur corpora sanctorum martirum Eulogii et Lucrecie et beate 
Eulalie Emeritensis et sancti Pelagii martiris et sancti Vincentii martiris adque abbatis et sancti Serani episcopi et sancti Iuliani Pomerii, qui arcam ipsam a Toleto Ouetum transtulit, et corpus regis Casti, qui ecclesiam Sancti Saluatoris fundauit. Crux ibi monstratur opere angelico fabricata. Sporte apostolorum Petri et Andree. Lignum cuiusdam trabis deficientis ad edificium ecclesie quod Deus mirabiliter augmentauit. In ipsa autem principali ecclesia habetur una de sex idriis in quibus Dominus aquam uertit in uinum.

Quisquis autem diuina inspiratione uocatus tam preciosa sanctorum insignia uisitare meruerit, auctoritate Dei et beatorum apostolorum Petri et Pauli et a Romana Ecclesia ipsi ecclesie Sancti Saluatoris hac auctoritate concessa sciat sibi ab episcopo eiusdem sedis et a ministris eius terciam partem iniuncte sibi peniten(i)tie condonari et se in confraternitate ecclesie recipi, ita ut uir et femina faciat singulas missas celebrare singulis annis uite sue pro defunctis confratribus Ouethensis Ecclesie et in obitu suo mittat pro se oblationem, obolum aut denarium aut amplius que (?) uoluerit, et tunc sui confratres debita persoluent officia. Annuente Domino nostro, ualete.

La coincidencia de este documento con el Liber Testamentorum es evidente, salidos ambos de una misma fuente. En lo que hace a las reliquias, el códice de Valenciennes añade capilli en el caso de las reliquias de la Virgen y de Juan Bautista y la uirga con la que Moisés separó las aguas del Mar Rojo y omite la hydria que contenía el agua convertida en vino. Cambia además los nombres de Marta y María por el de María Magdalena, más de acuerdo con las fuentes literarias.

La diferencia fundamental entre ambos documentos es la adición que presenta el texto del códice francés, cuando dice que fuera del Arca se encuentran los cuerpos de los santos mártires de Córdoba Eulogio, Lucrecia y Pelayo, de Eulalia de Mérida, san Vicente de León, san Asturio Serrano y san Julián obispos de Toledo, confundido éste último, con Julián Pomerio, escritor judío anterior en dos siglos, y de Alfonso el Casto.

Añade también las sportae (bolsas) de los apóstoles Pedro y Andrés y el leño de una viga deficiente que Dios aumentó milagrosamente en la iglesia de San Salvador, reliquia esta última a la que también se refiere el Corpus Pelagianum (serie de documentos que recogen los hechos principales del obispado de Pelayo), como hacen saber Fernández Conde y Alonso Álvarez (2017: 69), quienes ańaden que el manuscrito del Corpus Pelagianum que recoge esta información, Madrid BN I5I3, fue escrito hacia II40 y de él habría tomado la información el autor del texto del manuscrito de Valenciennes, por lo que tal texto habría sido escrito posteriormente a esa fecha y los folios del códice francés en que se encuentra serían, por tanto, igualmente posteriores a II4O. El citado Corpus Pelagianum recoge de forma casi idéntica la lista de reliquias que presenta el Liber Testamentorum.

En relación con los protagonistas de los relatos del Pasionario Hispánico, el único citado es san Pelayo, adolescente originario de Galicia, mártir en la Córdoba musulmana, cuyos restos fueron trasladados a León en 967 y de allí a Oviedo durante el reinado de Vermudo II (985-999). Por lo demás, el Liber Testamentorum, el Corpus Pelagianum y el manuscrito de Valenciennes transmiten una misma historia.

En resumen, la narración de la procedencia del Arca, el contenido de sus reliquias, la alusión o el silencio sobre el rey Alfonso VI tienen diferencias fundamentales en los documentos situados en el paso del s. XI al s. XII. La razón es el hecho de la reconquista de Toledo, su nombramiento como sede primada de la Iglesia española, el desplazamiento de Oviedo y la muerte de Alfonso VI.

El texto de este mismo documento en el códice del s. XIII El Burgo de Osma, Bibl. del Cabildo, 8, ff. I99r20or, es prácticamente igual al del ms. Valenciennes 99, como se puede observar en la transcripción publicada hace unos años (cfr Calleja, 20II: 22O-22I). En el viaje del Arca Santa de Jerusalén a Oviedo se añade 
una escala más, Sevilla, entre Cartagena (o Cartago) y Toledo.

El manuscrito 804 de la Bibl. de Cambrai, s. XIII, ff. 68ra-7ova, se refiere igualmente a la procedencia del Arca (cfr Fernández Conde, I972: I62 ss.), que hace venir también de Jerusalén a Oviedo por Cartagena (o Cartago) y Toledo, y da una corta relación de reliquias: leche de la Virgen, parte de la cruz de Cristo y de la corona de espinas, un trozo de la roca del sepulcro, tierra del sitio desde el que ascendió a los cielos, parte de sus pańales, sangre procedente de una imagen suya atravesada por los judíos, un trozo de la vara de Moisés, maná, las bolsas de san Pedro y san Andrés, un trozo de la cuna de Jesús niño, la suela del calzado de san Pedro, cabellos de María Magdalena. Como se puede observar, el relato sigue la línea de los documentos literarios del s. XII, eliminando toda la relación de santos presentes en el Pasionario Hispánico.

El códice British Library, Harley 2253, s. XIV, contiene, ff. I3IV-I32r, el mismo relato que recogen los manuscritos de Valenciennes y El Burgo de Osma con mínimas diferencias. En el recorrido del Arca se incluye también Sevilla.

\section{RELIQUIA ESPECIAL}

En el texto del Liber Testamentorum y de los códices de Valenciennes, El Burgo de Osma y de la British Library se encuentra anotada una reliquia especial, esto es, el manto que entregó la Virgen a Ildefonso, obispo de Toledo, en recompensa, como dice el Liber Testamentorum, por haber escrito el tratado De uirginitate Sanctae Mariae. En el texto del Liber Testamentorum en el Arca se encontraba parte del manto, en el de los códices, la prenda entera. Este es el texto de los códices:

Pallium quod dedit ipsa regina celi Ildefonso Toletane sedis archiepiscopo.

En el Liber Testamentorum la cita, con el mismo inicio, es más larga:
De pallio quod dedit ipsa Regina Celi Hildefonso Toletane sedis archiepiscopo, pro laudibus in honore sancte ipsius uirginitatis celebratis, ubi ipse episcopus gloriose contulit aduersus heresiarcas Eluidium atque Iouinianum, sic dicens illi circunstantibus tam angelorum quam etiam sanctorum multiplicibus choris inenarrabili luce circunscriptis: 'accipe hoc munus quod tibi de thesauro Filii mei attuli.

El obispo Pelayo y su equipo conocían tanto el tratado De uirginitate Sanctae Mariae, escrito por Ildefonso obispo de Toledo (657-667), como el relato hagiográfico Vita uel Gesta sancti Ildefonsi, al que nos vamos a referir a continuación. En el tratado, en efecto, dos de los heréticos contra los que arguye Ildefonso en defensa de la virginidad de María son Helvidio y Joviniano y, de otro lado, la situación y las palabras que dirige la Virgen a Ildefonso, cuando le entrega el manto, son las mismas, accipe...adtuli, que se encuentran en la Vita uel Gesta (cfr Yarza, 2006: 279-325):

subito ostia aperientes et ecclesiam intuentes atque splendori caelesti oculos defigentes.. Et eleuatis oculis, aspexit in circuitu eius et uidit omnem absidam ecclesiae repletam uirginum turmis de canticulis Dauid modulata suauitate aliquid decantantes. Aspiciensque [Ildefonsus] in eam, ut ipse sibi bene consciis et bene carissimis referebat, sic eum adlocuta est [Maria] uoce: "Propera in occursum, serue Dei rectissime, accipe munusculum de manu mea, quod de thesauro Filii mei tibi adtuli; sic enim tibi opus est ut benedictione tegminis, quae tibi data est, in meo tantum die utaris; et quia oculos fidei fixos in meo semper seruitio tenens permansisti, et laudem meam, diffusa in labiis tuis gratia, dulciter in cordibus fidelium depinxisti, ex uestimentis ecclesiae iam in hac uita ornatus eris et in futuro in promptuariis meis cum aliis seruis Filii mei laetaberis». 
El códice El Escorial a. II. 9, s x, que transmite el tratado De uirginitate, contiene en el folio inicial la cruz de Oviedo en colores, por lo que se piensa que procede de allí. Por tanto, no sería raro que dicha obra de Ildefonso se conociera en Asturias. Y así mismo una copia de la Vita uel Gesta, relato escrito, a nuestro juicio, a fines del s. XI, debía de encontrarse en la región o, al menos, Pelayo lo conocía quizá por su supuesta estancia en Sahagún, adonde habría llegado desde Toledo o, quizá mejor, desde Cluny.

La Vita uel Gesta, narración hagiográfica, cuenta la resurrección de santa Leocadia y la aparición de la Virgen a Ildefonso, obispo de Toledo (657-667), a quien entrega un vestido en regalo por el tratado $D e$ uirginitate Sanctae Mariae escrito por Ildefonso. En nuestro estudio sobre la Vita uel Gesta decíamos que el relato está atribuido en los códices a Eladio, obispo de Toledo, hecho imposible ya que Eladio falleció en 633 e Ildefonso en 667, y proponíamos que habría sido escrito por un monje de Cluny, seguramente uno de los litterati cluniacenses que acompañaron al cluniacense Bernardo de la Sauvetat a Toledo, nombrado arzobispo de la ciudad en I086, al año siguiente de la reconquista de la ciudad. Uno de los objetivos de la redacción de la Vita uel Gesta habría sido el ensalzamiento de la sede toledana, ocupada ahora por un monje de Cluny, y la difusión del culto mariano, ya que el relato hagiográfico en Cluny se unió en los códices al tratado De uirginitate de Ildefonso, ilustre antecesor de Bernardo cuatro siglos antes, y se expandió por toda Francia. El tratado de Ildefonso era ya conocido en Cluny porque una copia había viajado a su monasterio desde Le Puy-en-Velay, donde se encontraba el manuscrito conteniendo el tratado ildefonsiano, copiado en Albelda (Logrońo) por el monje Gómez en el año 950 para Gotiscalco, obispo de Le Puy, códice Paris BnF 2855 .

Existen dos familias de códices del relato de la Vita uel Gesta sancti Ildefonsi, una cluniacense y otra, hispana, de las que es mejor la primera. De acuerdo con el estudio de los manuscritos, el códice más antiguo en recoger el relato es un ejemplar que es copia del de Gómez, esto es, el cluniacense Paris BN nouv. acq. lat. $1455(X)$, en el que fue incluida la Vita uel Gesta (cfr Garand, I979:
I63-I80), en la segunda mitad del s. XI, entre I086-I090, a nuestro juicio. Del códice $X$ fueron copiados, con cambios en algunas lecturas, los ejemplares cluniacenses A I $a s^{2}$, aproximadamente hacia Iogo.

El códice $I$ fue regalado por Hugo, abad de Cluny, al rey Alfonso VI. En la Pascua de Iogo el abad y el rey mantuvieron un encuentro en Burgos para confirmar una aportación económica por parte real a cambio de protección espiritual. Por esas fechas se había construido la iglesia de Cluny con fondos proporcionados por el rey leonés. Es posible que en tal encuentro de Burgos el abad hiciera entrega al rey del precioso códice, decorado con treinta y cinco miniaturas, como regalo del monasterio. En esa época la relación entre Cluny y la monarquía leonesa-castellana fue muy intensa, reforzada por el matrimonio de Alfonso VI con Constanza de Borgońa (ella muere en I093). La familia de códices cluniacenses se incrementó más tarde con numerosos ejemplares.

La familia hispana, compuesta por los códices $E M R$ $B D^{3}$, contiene un texto de la Vita uel Gesta peor que el cluniacense, tomado muy posiblemente de un ejemplar de Cluny y manipulado en su copia. Los códices emilianenses $E$, s. x., y $M$, s. XI, incorporaron el relato hagiográfico a fines del s. XI, después de haber sido copiado el resto de su contenido, como precisan Antolín (I9IO, p. 368) y Díaz (I979, p. I82). El códice italiano $R$ fue copiado en la segunda mitad del s. XI o inicios del XII, según varios autores (Poncelet, 196I: 36I-363; Giogetti - Mottironi, I96r: 297-30I; Chiesa, I989: I46-150), y en el s. XII (Díaz, I958: 547), por lo que, en cualquier caso, su datación más antigua remontaría a fines del s. XI. El códice $B$, procedente de Silos, fue copiado en IIo9 y el manuscrito $D$, en el s. XIII-XIV. Por tanto, los manuscritos más antiguos que contienen la Vita uel Gesta fueron copiados a fines del s. XI, ninguno antes.

De otro lado, el Liber Testamentorum y el códice de Valenciennes, los documentos más antiguos que aluden

\footnotetext{
${ }^{2}$ Códice $A$ = Paris BnF lat. 2359. Cód. $I$ = Parma Bibl. Palatina I650. Cód. $a=$ Paris Bibl. Arsenal 372. Cód. $s=$ Paris Bibl. Arsenal 37I.

${ }^{3}$ Códice $E=$ El Escorial d. I. I. Cód. $M=$ Madrid Bibl. Academia de la Historia 47. Cód. $R=$ Roma Bibl. Vallicelliana tomo XXII. Cód. $B=$ London Bitish Library Addit. II695. Cód. $D$ = Salamanca Bibl. Univers. 2537.
} 
al manto regalado por la Virgen a Ildefonso como reliquia del Arca Santa de Oviedo, son del s. XII. Ello hace que nos reafirmemos en nuestra hipótesis de que el relato hagiográfico se redactó a fines del s. XI.

El manuscrito ya citado Cambrai 804, s. XIII, narra, f. 68va, el milagro de la entrega de un vestido, un alba (Guscin, 2006: I46), por la Virgen a Ildefonso en agradecimiento por haber escrito en su honor el tratado $D e$ uirginitate. El relato está tomado de la obra De miraculis sanctae Mariae, 3 , escrita por el benedictino inglés Guillermo de Malmesbury (muere hacia II43), o bien de otra obra que depende de la del anterior autor, esto es, la colección Miracula sanctae Mariae, de su relato $\mathrm{n}^{\circ}$ I (Canal, I967: 437-462). En ambos casos la narración depende de la Vita uel Gesta sancti Ildefonsi, que de Cluny se había expandido por toda Europa.

Dos de los códices, los emilianenses $E M$, como decíamos en nuestro estudio de la Vita uel Gesta, borraron en el título, como se puede observar claramente, la atribución del relato a Eladio, porque el copista advirtió la anomalía histórica, y pusieron en su lugar el nombre de Cixila, obispo de Toledo entre 744-753 o, según otros autores, entre 774-783.

R. Gonzálvez (2018: 393-4II), basándose en el título reconstruido de los códices de San Millán, escribió a favor de la hipótesis de que el relato había sido escrito por Cixila, argumentando en contra de nuestra teoría de la redacción del relato por un monje de Cluny, ayudado por algún clérigo mozárabe toledano, a fines del s. XI. Gonzálvez no se refería en su artículo al hecho, dado a conocer por nosotros, de que el título había sido manipulado y alterado. Sin embargo, todas las referencias de fechas dejan bien claro que el relato no fue conocido hasta finales del s. XI. Por otra parte, el manto regalado por la Virgen no aparece en la relación de reliquias que recogen la inscripción del Arca Santa y el Acta de la apertura, cosa inaudita, en nuestra opinión, si el relato hubiera sido escrito en el s. viII.

De otro lado, Gonzálvez argumenta que el relato no pudo ser escrito por alguien del círculo de Bernardo de la Sauvetat dado que éste había sido nombrado arzobispo de Toledo para sustituir el rito hispano por el romano y en el relato de la Vita uel Gesta los protago- nistas son personajes como Leocadia e Ildefonso, pertenecientes a la mejor época del rito hispano. Gonzálvez, sin embargo, en otro artículo (1990: 9-33) se asombra de que en Toledo el rito hispano en la liturgia se mantuviera durante siglos. En nuestra opinión, Bernardo a su entrada en Toledo tuvo que hacer concesiones a los grupos mozárabes para granjearse su favor, ya que se hacía raro que tras la reconquista de la ciudad un galo ocupara la sede del primado de Hispania y viniera a liquidar el rito hispano. El relato de la Vita uel Gesta parece un homenaje del recién llegado, es decir, Bernardo, a figuras eternas de la ciudad como Leocadia e Ildefonso, incluso a Eladio, convertido en glosador de ambos por el autor del relato. No explica Gonzálvez el hecho asombroso de que hubiera escrito el relato el obispo Cixila y en todos los códices, menos en los manipulados y en sus copias, aparezca como autor el obispo Eladio.

La prenda que regala la Virgen a Ildefonso recibe en el relato de la Vita uel Gesta el nombre de tegmen, un vestido inconcreto. En todos los documentos que hemos visto relacionados con las reliquias del Arca Santa el vestido es un pallium, es decir, un manto. Más tarde, algunos autores, al referirse a la prenda, la denominan casulla, como es el caso del benedictino Herman de Laon (primera mitad del s. XII), quien elabora su relato hagiográfico Vita sancti Ildefonsi sirviéndose de la Vita uel Gesta, y otros, alba, como Guillermo de Malmesbury (primera mitad del s. XII) en su relato De sancto Hildefonso episcopo Toletano, tomado igualmente de la Vita uel Gesta.

\section{CONCLUSIONES}

I. El Acta de apertura del Arca Santa en 1075 en presencia del rey Alfonso VI se encuentra en dos documentos del s. XIII. Puesta en duda por algunos, es, a nuestro juicio, auténtica, tal como se deduce de su coincidencia con el texto de la inscripción grabada en la propia Arca. El Acta de apertura y la inscripción del Arca son los dos testimonios más antiguos sobre las reliquias del Arca Santa de Oviedo. 
2. Los nombres de los santos, cuyas reliquias citan como presentes en el Arca el Acta de apertura y la inscripción del Arca, corresponden en su gran mayoría a los de los protagonistas de los relatos del Passionarium Hispanicum, colección hagiográfica de mártires de diferentes países reunida en Silos y en Cardeña en los siglos X y XI. Este hecho, desapercibido hasta la fecha, ha permitido que hayamos podido mejorar el texto del Acta de apertura y de la inscripción esculpida en el Arca.

3. La relación de reliquias en el Arca Santa presente en los documentos de fines del s. XI y en los de inicios del s. XII es diferente. Ello es debido a la conversión de Toledo con el rey Alfonso VI en la sede del primado de Hispania en 1088 y al consiguiente desplazamiento de otras sedes, entre ellas Oviedo. El obispo de Oviedo Pelayo, a la muerte del rey Alfonso VI, reacciona y de- fiende su diócesis modificando en sus documentos la relación de nombres y reliquias del Arca Santa. El Liber testamentorum de Pelayo y pequeñas crónicas coincidentes con su texto, presentes en algunos códices, dan cuenta de la nueva política de la Iglesia ovetense.

4. La narración hagiográfica Vita uel Gesta sancti Ildefonsi recoge la entrega de un vestido por parte de la Virgen a san Ildefonso como recompensa por haber escrito el tratado De uirginitate sanctae Mariae. Tal prenda aparece entre las reliquias presentes en el Arca Santa que citan los documentos del s. XII, no los anteriores. Como se desprende de los datos que aportamos, la Vita uel Gesta fue escrita a fines del s. XI, no antes.

5. Ofrecemos la transcripción del texto que transmite el códice Valenciennes 99 y, al final, en Apéndice, la edición crítica de un documento excepcional, esto es, el Acta de apertura del Arca Santa en I075. 
APÉNDICE

ACTA DE APERTURA DEL ARCA SANTA DE OVIEDO EN I075. EDICIÓN CRÍTICA.

\section{CONSPECTVS SIGLORVM}

$A$ Oviedo, Archivo de la Catedral, serie B, carpeta 2, no $9 \mathrm{~A}$ - s. XIII

$B$ Oviedo, Archivo de la Catedral, serie B, carpeta 2, no ${ }_{9} \mathrm{~B}-\mathrm{s}$. XIII

Anno ab incarnatione Domini nostri Ihesu Christi Mo LXXVo. Apicem regni tenente Adefonso filio, Fredenandi magni quondam regis filio, apud Ouetensem Sancti Saluatoris episcopalem sedem predicto imperatore quadragesime tempus sollempniter in diuina religione celebrante cum sua nobilissima germana nomine Vrraca atque cum episcopo Bernardo sedis Palentine et Simeone

5 Auzensis ecclesie pontifice et Ariani, qui in predicta ecclesia presulatus officium fungebatur, contigit quoddam, diuina miseratione, reuelacionis donum per ipsius regis studium, siquidem thesaurum magno honore uenerandum, quod magna antiquitate in eadem ecclesia manebat occultum, Christus suo fidelissimo principi ad laudem et gloriam nominis sui uoluit manifestare.

Nam priscis temporibus cum Deus omnipotens propter culpam christianorum subiugasset totam

Io pene Yspaniam populo Ismahelitarum, omnes sanctorum reliquias patrum, quasque fideles ex diuersis locis subripere potuerunt, apud Tholetanam urbem congregantes et in quadam archa studiose condientes penes se aliquanto tempore tenuerunt. Cum uero cernerent tam inmanissimam stragem fieri fidelium populorum, non habentes spem ultra alterum confugium faciendi, prouidente diuina clemencia, que locum suo nomini edificatum exaltare disponebat, salubre

Is consilium inuenerunt ut ad ipsum quem nouerant tuitionem locum iam dictam archam dirigerent, ut ibi se suosque Domino comendarent.

Cum igitur ita omnia acta fuissent sicut disposuerant, mansit illo in loco longo post tempore incognitum quod in ea detinebatur absconditum, quousque ad illud tempus uentum est quo quidam magne uirtutis uir, Poncius nomine, suscepit pontificatus honorem. Suis itaque temporibus cum 20 cognouisset a quibusdam fidelibus magna illic quedam detineri, uoluit sicut audierat probari. Aperire autem gestiens tectum arche cum aliquibus ex suis abbatibus ac clericis, tanta lux emicuit ab illa, ut pre ipso splendore oculi non possent aspicere que habebantur intra claustra arche, ubi detinebantur cara sanctorum Dei pignora peneque cuncti terre consternerentur pre timoris magnitudinem. Occulto itaque Dei iudicio, fuscati quadam cecitate ita intacta reliquerunt sicut

25 hactenus fuerant. Quidam uero ex ipsis in eadem quam acceperant cecitate usque ad finem sue uite permanserunt.

Interea surrexit serenissimus Dei cultor Adefonsus rex iam prenominatus, in cuius temporibus rex pacis et rex omnium seculorum Deus palam cunctis patefecit quod dudum uoluerat esse occultum. Memoratus ergo imperator Deo adherens seque illi tota deuotione commitens monuit se

5 ariani] abani $B \quad \| \quad 6$ contigit] Risco, contineret $A B \|$ quoddam] quodam $A \quad \| \quad$ ro quasque] scripsi, quique $A B \quad \| \quad$ II tholetanam] tholetanum $A \quad \| \quad$ I3 stragem] stratem $A \quad \| \quad$ ultra] ultra ad $A$, alteram ad $B \quad \| \quad$ I4 prouidente] prouidendi $A \quad \| \quad$ I6 se suosque] seruosque $B \quad \| \quad$ I8 quod] scripsi, que $A B$

Trad. text: $A B$ 
30 cum presbiteros prefatos ac ceteros qui intra curiam aule regie uersabantur ac totum reliquum uulgus ieiunio plus solito quadragesimali tempore corpora affligi et sacrificiis et orationibus intentos clericos tholetanos illic habitantes esse precepit et reliquos Romanum ritum tenentes ortatur Dominum precibus flagitare, ut ille qui olim de celo descendere et hominibus se palpabilem prebere uoluit, ipse eis dignaretur manifestare propter nimiam suam caritatem, qua nos dilexit, ea

35 que tam diucius hominibus ignota intra predictam archam detinebantur. Domini autem misericordia ita actum est, quia omnes homines uult saluos fieri et ad agnicionem ueritatis uenire, sicut ipse optauerat.

Nam mediante quadragesima, IIIo idus martii, VIa feria, circa horam terciam, episcopi et presbiteri missarum solemniis celebratis cum concentu psallencium clericorum, ad locum usque 40 perueniunt destinatum ubi reconditum habebatur munus tam copiosum. Leui autem motu cum magno timore aperientes, turibulis hinc atque illinc timiamatha fumiuoma flagrancia reddentibus, repererunt hoc in propatulo quod a Deo poposcerant, scilicet incredibile thesaurum. Id est, de ligno Domini. De cruore Domini. De pane Domini, id est, de cena ipsius. De sepulchro Domini. De terra sancta ubi Dominus stetit. De uestimento Sancte Marie et de lacte ipsius uirginis ac genetricis

45 Domini. De uestimento Domini sorte partito et de sudario eius. Reliquias de sancto Petro apostolo, sancti Thome, Bartholomei apostoli. De ossibus prophetarum, sanctorum Iusti et Pastoris, Adriani et Natalie, Mame, Iulie, Verissimi et Maxime germani, Bauduli, Pantaleonis, Cipriani, Eulalie, Sebastiani, Cucufatis. De pallio sancti Sulpicii, sancte Agate, Emeterii et Celedoni, sancti Iohannis Babtiste, sancti Romani, sancti Stephani prothomartiris, sancti Fructuosi, Augurii et

50 Eulogii, sancti Victoris, sancti Laurentii, sanctarum Iuste et Rufine, sancti Seruandi et Germani, sancti Liberi, sanctarum Maxime et Iulie, sancti Cosme et Damiani, sancti Sergii et Bachi, sancti Iacobi fratris Domini, sancti Stephani pape, sancti Christofori, sancti Iohannis apostoli, uestimentum sancti Tirsi, sancti Iuliani, sancti Felicis, sancti Andree, sancti Petri exorciste, sancte Eugenie, sancti Martini, sanctorum Facundi et Primitiui, sancti Vincenti leuite, sancti Fausti,

55 sancti Iohannis, sancti Pauli apostoli, sancte Agne, sancti Felicis, Simplicii, sancti Faustini et Beatricis, sancte Petronille, sancte Eulalie Barcinonensis. De cineribus sanctorum Emiliani diaconi et Iheremie martirum, sancti Rogelli, sancti Serui Dei martiris, sancte Pompose, sanctorum Ananie, Azarie et Misaelis, sancti Sportelii et sancte Iuliane et aliorum quam plurimorum, quorum numerum sola Dei sciencia colligit.

60 Ego igitur Adefonsus, Dei nutu rex, quia Dominus noster fecit meis temporibus tam copiosum munus, ideo in ipsius nomine uolo honorare illam domum eius ubi hec reliquie sunt reperte, ut ibi habitantes habeant ex mea quantitate aliquantulum presentis uite solacium, ut studiosius possint Deo placere et uigilancius sacrificium illi iusticie et laudis offerre. Dono enim bono animo et

30 presbiteros] episcopos $A \quad \| \quad$ uersabantur] uenerantur $B \quad \| \quad 32$ intentos] intentis $A \quad \|$ habitantes] scripsi, habitantibus $A B \|$ tenentes] scripsi, tenentibus $A B \quad \| \quad 34$ qua] quam $A \|$ nos $\operatorname{dilexit]~dilexit~}$

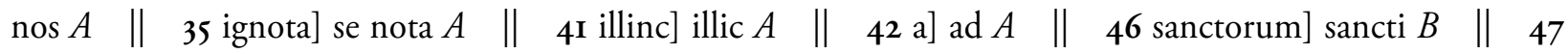
mame] mamme $B \quad \| \quad$ maxime] scripsi, maximi $A B \quad \|$ bauduli] baudili $B \quad \| \quad 48$ cucufatis] scripsi, cucufati $A B \quad \| \quad$ pallio] palleo $A \quad \| \quad$ 5o sancti 2] sancte $A \quad \|$ sanctarum] sancte $B \quad \| \quad$ 5I sanctarum] sancti $A$ $B \quad \| \quad$ maxime] maximi $B \quad \| \quad$ sancti 2] om. $A \quad \| \quad$ sancti 3] om. $A \quad \| \quad 53$ exorciste] exorcista $A \quad \| \quad 54$ sanctorum] sancti $B \quad \| \quad 55$ sancti 3] sanctorum $A \quad \| \quad$ sancti 4] om. $A \quad \| \quad 57$ sanctorum] om. $A$

Trad. text: $A B$ 
spontanea uoluntate omnipotenti Deo, Patri et Filio et Spiritui Sancto et beate Dei genetrici Marie

65 et omnibus sanctis apostolis uel omnibus sanctis eius quorum reliquie in ipsa continentur archa propter remedium peccatorum meorum, ut ipse me dirigat in uiam salutis eterne, qui pati uoluit pro me, et ut ipse me faciat feliciter regnum in pace gubernare, in misericordia et iudicio et in seculo futuro consociet cum eisdem sanctis in celesti regno, quandam mandacionem, que uulgo uocatur Lagneyum, qui constat esse regalis fiscus, qui fuit de meo attauo comite Sancio uel de meo auo rege 70 Adefonso sicut illi habuerunt uel tenuerunt omnia et in omnibus et per omnia cum suis notatis terminis sicut ego teneo, in primis quomodo uadit terminus per illam crucem de penna Corbaria et per Bouiolia et inde per Arrio et per cotum de Spinas et per Actiones et procedit ad Lamas et inde ad sancto Tirso et ab hinc ad Pando Iusti et per riuulo Cauo et sic transit ad pena Aoba et ab illo loco per directa linea ad Bouia et illinc ad illa forca de Virga Aurea et quomodo ascendit per

75 Cesuras et inde per Etratos et pergit per Azeuo et sic reuertitur ad penna Corbaria iam superius nominata.

Quantum infra omnes istas affrontaciones uel terminos includitur, quod ego habeo uel habere debeo per qualicumque uoce, sicut tenuerunt parentes mei cum ipsos eosdem muros, tam homines quam mulieres ex generatione ibi habitantes fuerint uel habitant aut ad habitandum uenerint, a

80 maximo usque ad minimo, presentes et futuros, sic dono domino Deo et omnes ad unum dominum, id est, episcopum Sancti Saluatoris de Oueto, seruiant perpetim nunc et in euum uel illis quibus ipse commiserit in tali uero pacto, ut nullus sayo neque uicarius illuc pro pignora nec pro homicidio neque pro fossataria neque pro nulla calumpnia uiolenter introeat neque nullus aliquis homo. Quod si fortasse aliquis, suadente diabolo uel instigante, maior persona uel minor, parui pendens uel mei

85 decreta collate rei intra per scriptis terminis uim aliquam inferre uoluerit, excepto opus perfregerit, quingentos solidos presumpcione componat episcopo presenti uel successoribus eius, et est manifestum. Si quis uero ab hodierno die et deinceps nunc testamentum uel decretum a me legitime pro anima mea uel pro regni mei gubernacione factum disrumpere uel auferre presumpserit, primo iram Dei incurrat et a liminibus sancte Dei Ecclesie extraneus existat et cum

90 Iuda Scariothe eterna supplicia sustineat nisi resipuerit. Et postmodum hec donacio firma stabilisque permaneat in omni euo. Amen. Factum testamentum uel decretum pridie idus martii, regnante domino nostro Iesu Christo sub era $\mathrm{M}^{\mathrm{a}} \mathrm{C}^{\mathrm{a}} \mathrm{XIII}$.

Ego Adefonsus rex Legionis et Gallecie atque Castelle et Asturiarum hanc donacionem domino Deo feci et sanctis prenominatis et scribere iussi et manibus propriis firmaui et testibus firmare

95 rogaui. Addo igitur ego Adefonsus rex quendam ferrarium quem uocant Eita Velasquiz, cognomento Aluito. Vrraca, gloriosi et magni imperatoris regis filia, confirmat. Geluira, regis similis filia, confirmat. Bernardus, sancte sedis Palentine Ecclesie pontifex, subscripsit. Pelagius

64 genetrici] scripsi, genetricis $A B \quad \| \quad 65$ archa] ecclesia $A \quad \| \quad 68$ uulgo] uulco $A \quad \| \quad 7$ I terminis] terminum $A \quad \| \quad \mathbf{7 2}$ bouiolia] bouiola $B \quad \| \quad$ et inde I] exinde $A \quad \| \quad$ actiones] actones $B \quad \| \quad 73$ iusti] iusta $A \quad \| \quad$ aoba] $\begin{array}{llllllllll}\text { auba } A & \| & 75 & \text { cesuras ] cessuras } A & \| & \text { corbaria] corbaira } A & \| & 77 \text { affrontaciones] afrontaciones } A & \| & 78\end{array}$ muros] usus $A \quad \| \quad 79$ ex - uenerint $]$ om. $B \quad \| \quad \mathbf{8 2}$ illuc] illic $B \quad \| \quad 83$ fossataria] fossatera $B \quad \| \quad 84$ uel 2] huius $B \quad \| \quad 86$ episcopo] apiscobo $B \quad \| \quad 88$ gubernacione] enkartacionem $B \quad \| \quad 89$ a $]$ ab $B \quad \|$ extraneus existat] tr. $A \quad \| \quad \mathbf{9 0}$ scariothe] scarioth $A \quad \| \quad \mathbf{9 2}$ nostro] om. $A \quad \| \quad \mathbf{9 3}$ legionis] legionensis $A \quad \| \quad 95$ quem $]$ que $A \quad \| \quad$ eita] cyta $B \quad \| \quad 96$ cognomento aluito] om. $A \quad \| \quad$ urraca] urracca $A \quad \| \quad$ confirmat] confirmo $B \quad \| \quad$ regis 2] $\sin$ ? $B \quad \| \quad 97$ confirmat] confirmo $B \quad \| \quad$ bernardus] bernarde $A$

Trad. text: $A B$ 
Legionensis sedis episcopus, confirmat. Petrus, sancte sedis Asturicensis antestis, confirmat. Scemenus, gratia Dei Auzensis Ecclesie presul, subscripsit. Gundissaluus, Dumiensis Ecclesie Ioo presul, subscripsit. Arias, sancte sedis Ouetensis Ecclesie episcopus, confirmat. Munnio comes confirmat. Petro Pelaiz comes confirmat. Pelagio Pelaiz confirmat. Garseani filius, Gomesani comes, confirmat. Fredenando Flaginiz, armiger regis, confirmat. Aluazil Sesnando Colimbriense confirmat. Comes Veila Ouequiz confirmat. Roderico Didaz confirmat. Petro Guterriz confirmat. Petro Ouequiz confirmat. Annaia Petriz confirmat. Petro Garseaz confirmat. Iohanne Ordonniz IOS confirmat. Eita Cidiz confirmat. Didaco Ordonniz confirmat. Pelagio Didaz confirmat. Alfonso Monniz confirmat. Veremundus Guterriz confirmat. Abbas domino Ranemiro confirmat. Item abbas domino Veila confirmat. Pelagius abba confirmat. Abbas domino Eita confirmat. Vendimius abba confirmat. Aluarus abba confirmat. Romanus primiclerus confirmat. Veremundus Iohannis confirmat. Martinus presbiter confirmat. Garsea iudex confirmat. Hic coram testibus Martinus testis confirmat. Flaino testis confirmat. Pelagio testis confirmat. Iohannes notarius regis qui hunc testamentum scripsit sub die et anno quo supra.

Notum sit cunctis hunc testamentum audientibus similem uel haberi intra abdita supradicte arce cum reliquiis sanctorum supradictorum.

98 legionensis] scripsi, legionense $A B \quad \|$ confirmat] confirmo $B \quad \| \quad$ antestis] antistis $B \quad \| \quad$ confirmat] confirmo $B \quad \| \quad 99$ scemenus] scemendus $B \quad \| \quad$ gratia] gratie $A \quad \| \quad$ Ioo confirmat] confirmans $B \quad \| \quad$ munnio] munio $A \quad \| \quad$ Ior gomesani] comesani $A$, gomessani $B \quad \| \quad$ IO2 fredenando] fredinando $A \quad \| \quad$ I03 ueila] uela $A \quad \| \quad$ I04 garseaz] garsea $A \quad \| \quad \operatorname{ordonniz}] \operatorname{ordoniz} A \quad \| \quad$ I05 ordonniz] ordoniz $A \quad \| \quad$ Io6 ueremundus] ueremudus $A$, ueremudo $B \quad \| \quad$ ranemiro] ranimiro $A \quad \| \quad$ item] om. $A \quad \| \quad$ Io7 eita] eitaz $B \quad \| \quad$ Io8 confirmat I] et add. $B \quad \| \quad$ ueremundus] ueremudus $A$, ueremudo $B \quad \| \quad$ Io9 hic] om. $A \quad \| \quad$ IIo testis I, 2, 3] om. $B \|$ confirmat $\mathrm{I}, 2,3] \mathrm{om}$. $A \|$ notarius] notario $A$

Trad. text: $A B$ 


\section{BIBLIOGRAFÍA}

Alonso, Raquel (2007-2008): «Patria uallata asperitate moncium. Pelayo de Oviedo, el arca de las reliquias y la creación de una topografía regia", Locus Amoenus, 9, p. 17-29.

Alonso, Raquel (2011): «El Corpus Pelagianum y el Liber Testamentorum eclesiae ouetensis: las 'reliquias del pasado' de la catedral de Oviedo y su uso propagandístico en la obra del obispo Pelayo de Oviedo (IIOI-II53)", in M. F. Alamichel et R. Braid (Dirs), Texte et Contexte. Littérature et Histoire del'Europe mediévále, Paris, p. 519-548.

Alonso, Raquel (20I4): «El obispo Arias y la apertura del Arca Santa de Oviedo: la reforma litúrgica antes del concilio de Burgos (Io80)", Medievalia, 17 , p. 79-IO2.

Alonso, Raquel (Ed.) (20I7): La Cámara Santa de la catedral de Oviedo y su relicario, Oviedo.

Alonso, RaQuel (2018): "De cruore Domini: La reliquia de la santa sangre en la catedral de Oviedo y el milagro del Cristo de Beirut", Medieval Studies in Honour of Peter Lineham, Firenze, SISMEL, p. 49-65.

Alonso, Raquel (2019): «Los dos Alfonsos: reyes, obispos y el Arca Santa de las reliquias de San Salvador de Oviedo", Historia R. Goiánia, n. I, p. 39-58.

Antolín, Guillermo (i9io): Catálogo de los Códices latinos de la Real Biblioteca del Escorial, I.

BANGo, IsIDRo G. (2OII): «La renovación del tesoro sagrado a partir del concilio de Coyanza y el taller real de orfebrería de León. El Arca Santa de Oviedo (IO72)", Anales de Historia del Arte, Volumen Extraordinario (2), p. II-67.

Calleja, Miguel (20II): «La traslación del Arca Santa a la catedral de Oviedo según el manuscrito número 8 de la catedral de Osma", Memoria Ecclesie, 36, Oviedo, p. 213-22I.

CAnal, José Ma (1967): "San Hildefonso de Toledo. Historia y leyenda», Ephemerides mariologicae, I7, p. 437-462.

Chiesa, Paolo (1989): «La traduzione latina del Sermo in reditu reliquiarum sancti Iohannis Chrysostomi di Cosma il vestitore eseguita da Guarimpoto grammatico", Aevum, 63, p. I46-I5o.

De Bruyne, Donatien (i927): "Le plus ancienne catalogue des reliquies d'Oviedo", Analecta Bollandiana, 45, p. 93-95.

Díaz y Díaz, Manuel C. (1958): Index scriptorum Latinorum medii aevi Hispanorum, pars prior.

Díaz y Díaz, Manuel C. (1979): Libros y librerías en la Rioja altomedieval.

FÁbrega, Ángel (1953): Pasionario Hispánico, Madrid-Barcelona.

Fernández Conde, Francisco Javier (I97I): El Libro de los Testamentos de la catedral de Oviedo, Roma.

Fernández Conde, Francisco Javier (1972): La Iglesia de Asturias en la alta Edad Media, Oviedo.

Fernández Conde, Francisco Javier (2013): "Las Reliquias y el Sudario de la Cámara Santa de Oviedo. Religiosidad y poder”, en Castilla y el mundo feudal (Homenaje al profesor Julio Valdeón), drs. Del Val Valdivieso, Ma. I.; Martínez Sopena, P. Vol. III, Universidad de Valladolid, Junta de Castilla y León, 549-566.
Fernández Conde, Francisco Javier; Alonso, Raquel (20I7): «Los catálogos de las Reliquias de la Catedral de Oviedo", Territorio, Sociedady Poder, $\mathrm{n}^{\circ} \mathrm{I} 2$, p. 55-8I.

Flórez, Henrique (1765): Viaje de Ambrosio de Morales por orden del rey D. Phelipe II. A los reynos de León, y Galicia y Principado de Asturias, Madrid, p. $70-73$.

Gambra, Andrés (1997): Alfonso VI, Cancillería, Curia e Imperio, León.

Garand, Monique-Cécile (I979): "Une collection personnelle de saint Odilon de Cluny et ses compléments", Scriptorium, 33, p. I63-I80.

García de Castro, César (20I6): «Datos y observaciones sobre el Arca Santa de la Cámara Santa de la catedral de Oviedo", Nailos, nº 3, p. I2I-I62.

GARCía de Cortázar, José ÁNGel (20I9): «Las reliquias y su utilización publicitaria en monasterios españoles de la edad románica», Instrumentos de publicidad espiritual y material en los monasterios medievales, Aguilar de Campoo.

Giorgetti Vichi, Anna Maria; Mottironi, Sergio (i96i): Catalogo dei manoscritti della Biblioteca Vallicelliana. Volume I, Istituto poligrafico dello Stato, Roma.

Gómez Moreno, Manuel (1934): El arte Románico español. Esquema de un libro, Madrid, p. 28-30.

Gómez Moreno, Manuel (1945): "El Arca Santa de Oviedo documentada", Archivo Español de Arte, 69, p. 6I-64.

GonzÁlvez, Ramón (I990): «La persistencia del rito hispánico o mozárabe en Toledo después del año Io80", Anales Toledanos, n 27, p. 9-33.

GonzÁlvez, Ramón (2018): San Ildefonso y otros obispos de la Iglesia visigótica y mozárabe de Toledo, Toledo.

Guiance, Ariel (20I8): «Memoria y reliquias en la Castilla medieval: de San Isidoro al Arca Santa de Oviedo", en J. Sánchez Herrero (coord.), San Isidoro de Sevilla en Sevilla, p. 203-223.

Guscin, Mark (2006): La Historia del sudario de Oviedo, Oviedo.

Harris, Julie A. (1995): "Redating the Arca Santa of Oviedo", The Art Bulletin, LXXVII/I, p. 84-93.

Henriet, Patrick (2006): «Oviedo, Jérusalem Hispanique au XII siècle. Le récit de la translation de l'Arca Sancta selon l'éveque Pélage d'Oviedo", Pèlerinages et lieux saints dans l'antiquité et le moyen âge, Mélanges offerts à Pierre Maraval, Paris, p. 235-247.

López Fernández, Enrique (2004): Las reliquias de San Salvador de Oviedo. Poncelet, Albertus (1909, ReImpr. 196I): Catalogus codicum hagiographicorum Latinorum bibliothecarum Romanarum praeter quam Vaticanae (Subsidia Hagiographica, 9), Bruxelles.

Rico, Daniel (20I7): «La inscripción histórica del Arca Santa de Oviedo. Nueva transcripción y edición", Territorio, Sociedady Poder, no I2, p. 37-53. Risco, Manuel (I793): España Sagrada, t. 38.

SAnZ, Ma Josefa (1995): Liber Testamentorum Ecclesiae Ouetensis, Barcelona. Yarza, VAleriano (2006): "La Vita uel Gesta sancti Ildefonsi de Ps. Eladio", Veleia, p. 279-325. 
